\title{
Síndrome de depresión de grasa láctea provocado por el isómero trans-10, cis-12 del ácido linoleico conjugado en vacas lactantes. Revisión
}

\section{Milk fat depression syndrome caused by trans-10, cis-12 isomer of conjugated linoleic acid in lactating cows. Review}

\author{
Lorenzo Danilo Granados-Rivera ${ }^{a}$ \\ Omar Hernández-Mendo ${ }^{\mathrm{b} *}$ \\ ${ }^{a}$ Campo Experimental General Terán. INIFAP. General Terán, Nuevo León. México. \\ ${ }^{\text {b }}$ Programa de Ganadería, Colegio de Postgraduados, Texcoco, México.
}

*Autor de correspondencia: ohmendo@ colpos.mx

\section{- Resumen:}

El objetivo fue discutir el efecto del isómero trans-10, cis-12 del ácido linoleico conjugado (ALC) en el síndrome de depresión de grasa láctea (SDGL) en vacas, caracterizado por reducir hasta en $50 \%$ la concentración de grasa en leche. Este síndrome causa menor rendimiento de derivados lácteos, por lo que el productor recibe menor pago por la leche. Diversas teorías explican la presencia del SDGL, siendo la biohidrogenación la mejor sustentada, donde establece que baja proporción de fibra detergente neutro o alta inclusión de ácidos grasos (AG) insaturados en la dieta de vacas lactantes, propician alteraciones en la biohidrogenación ruminal. Ello da origen a mayor producción de AG trans, que inhiben enzimas necesarias para la síntesis de AG en la glándula mamaria. El isómero trans-10, cis-12 ALC es uno de los principales responsables de la presencia del SDGL, cuyo mecanismo de acción no es claro aún, pero se sabe que dicho isómero suprime factores de transcripción que regulan la síntesis de grasa en leche.

- Palabras clave: Ácidos grasos, Síntesis de grasa, Biohidrogenación, Industria lechera. 


\section{- Abstract:}

The objective of this review is to discuss the effect of trans-10, cis-12 conjugated linoleic acid (CLA) on the milk fat depression syndrome (MFD) in dairy cows. The MFD is characterized by a reduction of up to $50 \%$ of fat concentration in milk, leading to lower yield of dairy products, and consequently, the farmer gets less payment for that milk. There are many theories that discuss MFD; however, the biohydrogenation is the one best supported, which states that a low proportion of neutral detergent fiber or high inclusion of unsaturated fatty acids (FA) into the diet of lactating cows, leads to alterations in ruminal biohydrogenation. This causes an increase of trans FA production, inhibiting those enzymes that are needed to synthesize FA in the mammary gland. The trans-10, cis-12 isomer of CLA is one of the main factors to develop MFD. However, the mechanism is still unclear, but it is known that such isomer suppresses transcription factors that regulate the synthesis of fat in milk.

- Key words: Fatty acids, Fat synthesis, Biohydrogenation, Dairy industry.

Recibido 05/12/2016

Aceptado 23/09/2017

\section{( Introducción}

La leche bovina tiene un elevado valor nutricional, cuya composición general es de $4.6 \%$ lactosa, $3.6 \%$ proteína y $4.2 \%$ grasa; esta última está compuesta por $98 \%$ de triglicéridos en promedio, los cuales están integrados por ácidos grasos (AG) de cadena corta (C4 a C8; $19.0 \%)$, cadena media (C10 a C14; $19.0 \%)$ y cadena larga (> C16; 62.0 \%). Los AG de C4:0 a C14:0 y la mitad del C16:0 se sintetizan de novo, mientras que el resto de $\mathrm{AG}$, incluyendo la segunda mitad del C16:0 provienen de la transferencia de AG preformados presentes en la sangre ${ }^{(1)}$. La síntesis de AG de novo en glándula mamaria se generan a partir de acético y butírico $^{(2)}$, y cuerpos cetónicos como acetoacetato y $\beta$-hidroxibutirato ${ }^{(3)}$. En tanto que la síntesis por transferencia, los AG son transportados en quilomicrones y lipoproteínas de muy baja densidad, como AG preformados no esterificados, transferidos desde el intestino delgado provenientes de la dieta o por movilización del tejido adiposo ${ }^{(3)}$. Por tanto, modificaciones en la producción de ácido acético y butírico en el rumen, así como el tipo de AG presente en la dieta, 
determinan la composición de AG en leche, y esta situación hace que la grasa láctea sea el componente de la leche más fácilmente modificable ${ }^{(4)}$.

$\mathrm{Al}$ respecto, la síntesis de grasa es muy sensible al cambio de dieta. Por ejemplo, dietas con menos de $25 \%$ de fibra detergente neutro (FDN), y más de $3.5 \%$ en carga ruminal de AG insaturados, esto es, carga que considera el total de la ingesta de AG insaturados, o la inclusión de ionóforos en la dieta $\left(\geq \text { a } 2.7 \mathrm{mg} \mathrm{L}^{-1} \mathrm{hr}^{-1}\right)^{(5,6)}$, pueden inducir un síndrome caracterizado por un bajo contenido de grasa en leche, reducción que puede ser hasta en $50 \%$, fenómeno conocido como síndrome de depresión de grasa láctea $(\mathrm{SDGL})^{(7,8,9)}$. Dicho síndrome es también inducido por la adición de ácido linoleico conjugado (ALC) en la dieta, siendo el isómero trans-10, cis-12 del ALC el principal responsable ${ }^{(9)}$.

El ALC hace referencia a un conjunto de al menos 26 isómeros geométricos y posicionales del ácido linoleico con enlaces dobles en posición conjugada ${ }^{(9)}$, y es producido en el rumen como intermediario en el proceso de biohidrogenación del ácido linoleico, por acción de bacterias ${ }^{(10)}$ como Butirivibrio fibrisolvens ${ }^{(11)}$ y Megasphaera elsdenii ${ }^{(12)}$. El ALC, también puede ser sintetizado de forma endógena en los tejidos de rumiantes a partir de ácido vaccénico (C18: 1 trans-11), por acción de la esteril-CoA desaturasa $^{(13)}$. La importancia del ALC radica en su potencial efecto anticancerígeno y su reducción de grasa en tejido adiposo y muscular, atribuido a sus isómeros cis-9, trans-11 y trans-10, cis-12 ${ }^{(14,15)}$. En particular, el isómero trans-10, cis-12 ALC se asocia con una disminución en la concentración de grasa en leche (SDGL) ${ }^{(8)}$. Durante el SDGL hay una reducción de la síntesis de todos los AG presentes en la leche de rumiantes, siendo mayor en la síntesis de novo de AG respecto a la absorción de AG preformados $^{(9)}$, por tal motivo son mayormente afectados los AG de cadena corta y cadena media respecto a los de cadena $\operatorname{larga}{ }^{(7)}$, debido a que los primeros son sintetizados de novo mientras los segundos en su mayoría son absorbidos desde la sangre como AG preformados ${ }^{(16)}$.

Para la industria lechera el SDGL no es conveniente debido a un menor rendimiento de subproductos como queso y mantequilla, y para el productor representa menor pago por la leche. Las condiciones de alimentación que causan SDGL están bien establecidas ${ }^{(7,9)}$, por lo que se puede predecir el nivel de caída de la grasa en leche con relativa facilidad $^{(8)}$. Sin embargo, los mecanismos que causan SDGL no están del todo claros ${ }^{(17)}$, por lo que es necesario generar información para proponer estrategias de alimentación que ayuden a contrarrestar este problema. Al respecto, se han propuesto algunas teorías para explicar el SDGL, por lo que el objetivo de esta revisión bibliográfica es discutir dichas teorías y recopilar los avances más relevantes de los mecanismos que causan el síndrome de depresión de grasa láctea para ayudar a generar propuestas de solución a este problema. 


\section{Síntesis de grasa en leche}

\section{- Origen de la grasa láctea}

La grasa láctea en rumiantes tiene mayor proporción de AG saturados respecto a la de animales monogástricos ${ }^{(1)}$, que depende de modificación de lípidos dietarios durante la fermentación ruminal ${ }^{(17)}$, que sigue dos rutas, la lipólisis y biohidrogenación ruminal. La primera consiste en la acción de lipasas presentes en el rumen sobre los enlaces éster que unen los AG y los alcoholes, que al ser hidrolizados liberan los AG al medio ${ }^{(17)}$. La segunda consiste en una serie de reacciones enzimáticas secuenciales, que incluyen isomerización e hidrogenación, saturando así los AG insaturados, donde las bacterias Butirivibrio fibrisolvens y Megasphaera elsdenii son las principales responsables del proceso $^{(18)}$. Durante la biohidrogenación se forma el ácido esteárico ${ }^{(17)}$, por lo que los AG absorbidos en intestino delgado de origen dietario son mayormente AG saturados (70 \%), y únicamente del 10 a $15 \%$ de AG insaturados escapa a la biohidrogenación ruminal $^{(17)}$. Ello explica la alta proporción de AG saturados en grasa láctea de rumiantes, aunque en leche de vaca, los AG no depende exclusivamente de los AG dietarios, también son sintetizados de novo ${ }^{(1)}$. Al respecto, Palmquist y Mattos ${ }^{(19)}$ reportan que aproximadamente el $40 \%$ de AG en leche bovina se origina de la síntesis de novo, en tanto el $60 \%$ restante proviene de la absorción y transferencia de AG preformados procedentes en su mayoría de la dieta.

\section{- Síntesis de novo de ácidos grasos}

En los rumiantes, la síntesis de AG de novo se realiza en las células epiteliales de la glándula mamaria, y utiliza como fuentes de carbono al acetato y butirato derivados de la fermentación ruminal de los carbohidratos $^{(2)}$. Estos ácidos grasos volátiles son absorbidos en la circulación portal a través de la pared del rumen, donde el butirato es metabolizado ampliamente a $\beta$-hidroxibutirato, mientras que sólo una pequeña cantidad de acetato es metabolizada antes de entrar en la circulación sanguínea ${ }^{(20)}$. Es importante mencionar que cantidades considerables de acetato endógeno se producen a partir de 
acetil-CoA en hígado $^{(21)}$ y glándula mamaria ${ }^{(22)}$. El $\beta$-hidroxibutirato aporta alrededor del $8 \%$ del carbono utilizado para sintetizar la grasa láctea, y aproximadamente dos de los cuatro átomos de carbono en el extremo metilo terminal de los AG sintetizados de novo se derivan del $\beta$-hidroxibutirato, y la otra mitad, se derivan del acetato ${ }^{(23)}$. El $\beta$ hidroxibutirato es oxidado en la mitocondria por la enzima $\beta$-hidroxibutirato deshidrogenasa, produciendo acetil-CoA, la cual no puede utilizarse para la lipogénesis que ocurre en el citosol. Por lo tanto, la contribución de butirato a la síntesis de AG está limitada principalmente a la síntesis de los cuatro carbonos iniciales de la cadena carbonada de los $\mathrm{AG}^{(24)}$. Es preciso señalar que, en rumiantes, la glucosa no es un precursor de la síntesis de AG, debido a que la actividad de las enzimas ATP citrato liasa y NADP malato deshidrogenasa son extremadamente bajas en el tejido mamario $^{(25)}$.

La síntesis de AG de novo inicia cuando el acetato es activado a acetil-CoA y, por medio de la enzima acetil-CoA carboxilasa alfa, se forma malonil-CoA ${ }^{(26)}$. Una vez sintetizado malonil-CoA, la síntesis de AG se realiza por elongación o alargamiento de la cadena carbonada, mediante el complejo enzimático ácido graso sintasa, a través de reacciones sucesivas de condensación decarboxilativa de moléculas de acetil CoA (o butiril CoA) con malonil CoA, extendiendo así la cadena hidrocarbonada con dos átomos de carbono por cada ciclo, hasta un máximo de $16^{(27)}$. Cada ciclo requiere dos moléculas de equivalentes reductores $(\mathrm{NADPH}+\mathrm{H}+)^{(26)}$, generadas a partir del ciclo de la pentosa fosfato y la oxidación de isocitrato mediante la isocitrato deshidrogenasa ${ }^{(24)}$.

\section{- Absorción y transferencia de ácidos grasos a grasa en leche •}

En la glándula mamaria de la vaca, no es posible la condensación sucesiva de acetil CoA con malonil CoA para alargar la cadena de AG a más de 16 carbonos debido a que no existen las enzimas necesarias para la elongación ${ }^{(26)}$. Por tanto, los AG C16:0 y C18:0, utilizados para la síntesis de la grasa láctea en glándula mamaria tienen dos orígenes: 1) triglicéridos transportados en quilomicrones y en lipoproteínas de muy baja densidad de origen mayoritariamente intestinal, y 2) ácidos grasos no esterificados, principalmente palmítico C16:0, esteárico C18:0, y oleico C18:1 cis-9, movilizados desde el tejido adiposo $^{(28)}$. Los triglicéridos provenientes de la dieta se adhieren a quilomicrones y son hidrolizados por la enzima lipoproteína lipasa, separando a los AG y al glicerol ${ }^{(29)}$. Los AG libres y el glicerol son absorbidos en las células alveolares del tejido mamario donde son utilizados para la síntesis de grasa en leche ${ }^{(27)}$. Del total de AG absorbidos en el 
intestino delgado que provienen de triglicéridos de la dieta, entre 50 y $60 \%$ son transferidos a la leche ${ }^{(24)}$. En tanto, menos del $10 \%$ de AG movilizados de reservas corporales son transferidos a la leche ${ }^{(2,3)}$. Sin embargo, cuando las vacas están en balance energético negativo, la transferencia a partir de AG movilizados del tejido graso aumenta en proporción directa a la magnitud del déficit de energía ${ }^{(3)}$.

\section{V Ácido linoleico conjugado (ALC)}

El término ácido linoleico conjugado (ALC) hace referencia a un conjunto de al menos 26 isómeros geométricos y posicionales del ácido linoleico (Cuadro 1), los cuales poseen enlaces dobles en posición conjugada ${ }^{(7,9,30)}$. El isómero cis-9, trans-11 denominado ácido ruménico se degrada a ácido vaccénico (C18:1 trans-11), por efecto del proceso de hidrogenación del enlace cis-9, y dada la lentitud de esta fase, se acumula ácido vaccénico, ocasionando que una gran parte de éste escape del rumen y esté disponible para absorción intestinal ${ }^{(31)}$ (Figura 1).

Cuadro 1: Isómeros del ácido linoleico conjugado reportados en grasa láctea, queso y carne de bovinos

\begin{tabular}{ccc}
\hline Cis/Trans-18:2 & Cis/Cis-18:2 & Trans/Trans-18:2 \\
\hline trans-6,cis-8 & cis-7,cis-9 & trans-6,trans-8 \\
cis-7,trans-9 & cis-8,cis-10 & trans-7,trans-9 \\
trans-7,cis9 & cis-9,cis-11 & trans-8,trans-10 \\
cis-8,trans-10 & cis-10,cis-12 & trans-9,trans-11 \\
trans-8,cis-10 & cis-11,cis-13 & trans-10,trans-12 \\
cis-9,trans-11 & cis-12,cis-14 & trans-11,trans-13 \\
trans-9,cis-11 & & trans-12,trans-14 \\
cis-10,trans-12 & & \\
trans-10,cis-12 & & \\
cis-11,trans-13 & & \\
cis-12,trans-14 & & \\
trans-11,cis-13 & & \\
\hline
\end{tabular}

Adaptado de Collomb et a/(31) y Harvatine et a/(7). 
Figura 1: Síntesis del ácido linoleico conjugado en rumiantes

\section{Biosíntesis ruminal}

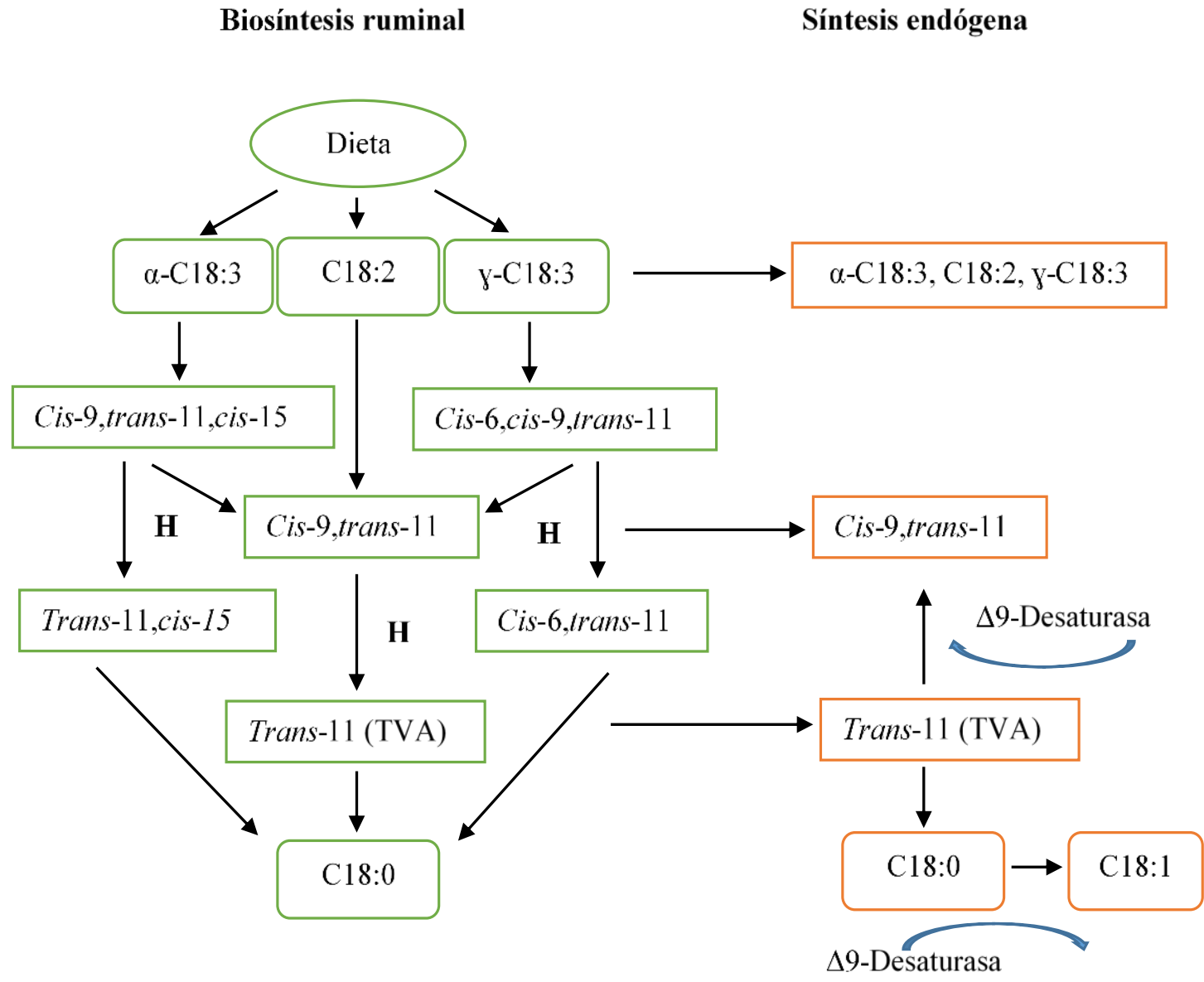

Adaptado de Collomb et al ${ }^{(31)}$.

El ALC también se sintetiza de forma endógena, a través de la desaturación del ácido vaccénico por acción de la delta $(\Delta)$ 9-desaturasa, enzima que se encuentra ampliamente distribuida en bacterias del rumen como Butirivibrio fibrisolvens, glándula mamaria y tejido adiposo ${ }^{(13)}$. La síntesis endógena del ALC es la principal vía de producción del isómero cis-9, trans-11 ${ }^{(13)}$, mientras que la síntesis del isómero trans-10, cis-12 es a través de la biohidrogenación ruminal exclusivamente ${ }^{(12)}$.

\section{Víndrome de depresión de grasa láctea (SDGL)}

El SDGL se observa en vacas lactantes y se caracteriza por una reducción de hasta $50 \%$ en la concentración de grasa en leche ${ }^{(7,9)}$, de igual forma se modifica la composición de 
AG en leche ${ }^{(7)}$, donde se reducen principalmente AG de cadena corta y cadena media ${ }^{(32)}$, con poco o nulo cambio en producción de leche ni en concentración de proteína y lactosa en leche ${ }^{(7,9)}$. Las condiciones de alimentación que provocan el SDGL son aquellas dietas con niveles bajos de FDN ( $<25 \%$ ), carga ruminal de AG insaturados $\geq 3.5$, inclusión de ionóforos en la dieta a dosis $\geq$ a $2.7 \mathrm{mg} \mathrm{L}^{-1} \mathrm{hr}^{-1(7,9)}$, o la combinación de estos factores de riesgo ${ }^{(6)}$. Al respecto, dietas bajas en FDN provocan $\mathrm{pH}$ bajos en el rumen, y con ello acumulación excesiva de ácido láctico, que promueve mayor síntesis de ácido propiónico y menor de acético y butírico ${ }^{(33)}$, mientras que los AG poliinsaturados y los ionóforos promueven la generación de AG trans a través de cambios en el metabolismo ruminal $^{(34)}$, condicionando así el síndrome de depresión de grasa láctea ${ }^{(7,9)}$.

Se han desarrollado varias teorías para explicar los cambios metabólicos en las vacas lactantes que condicionan la presentación del SDGL. Al respecto, se ha propuesto que el aumento en la proporción de ácido propiónico y disminución del ácido acético y butírico en rumen resulta en síntesis menor de $\beta$-hidroxibutirato, precursor necesario en la síntesis de AG, y ello induce menor concentración de grasa en leche ${ }^{(33)}$. También se ha sugerido que el aumento del ácido propiónico estimula mayor secreción pancreática de insulina, y con ello mayor suministro de energía hacia tejido muscular, adiposo y sanguíneo, lo cual representaría una competencia por nutrientes entre glándula mamaria y otros tejidos ${ }^{(35)}$. Sin embargo, a la fecha, no existe suficiente evidencia científica que sustente estas teorías ${ }^{(7,8,9)}$, excepto la de biohidrogenación propuesta por Bauman y Griinarii $^{(30)}$.

\section{- Teoría de biohidrogenación}

La teoría de biohidrogenación establece que las condiciones alimenticias como baja proporción de fibra detergente neutro (FDN) o alta inclusión de AG insaturados en la dieta de vacas lactantes propician alteraciones en la biohidrogenación ruminal que dan origen a producción mayor de AG trans, los cuales son capaces de inhibir enzimas necesarias para la síntesis de $\mathrm{AG}$ en glándula mamaria ${ }^{(30)}$. $\mathrm{Al}$ respecto, Griinari et al ${ }^{(36)}$ establecieron las bases de la teoría de biohidrogenación, al indicar que son necesarias dos condiciones a nivel ruminal para observar el SDGL en vacas lactantes, 1) alta disponibilidad de ácido linoleico o $\alpha$-linolénico y 2) un cambio en los procesos microbianos en el rumen. Ambas condiciones favorecerán la producción a través de la biohidrogenación ruminal del isómero trans-10, cis-12 ALC, principal responsable del $\operatorname{SDGL}^{(7,8,9)}$. Los AG linoleico y $\alpha$-linolénico dan origen a los isómeros trans-10, cis-12 ALC a través de isomerización enzimática, por lo que una disponibilidad alta en el rumen de dichos AG promoverá mayor concentración del isómero trans-10, cis-12 ALC en rumen, lo que a su vez permitirá una mayor tasa de escape de este isómero hacia 
glándula mamaria ${ }^{(12)}$, ocasionado disminución de grasa en leche. En tanto, una dieta baja en FDN genera pH bajo en rumen y cambios en las proporciones de los ácidos grasos volátiles, incrementándose la producción de ácido propiónico, y dichas condiciones favorecen el crecimiento de la población de bacterias Megasphaera elsdenii, bacterias

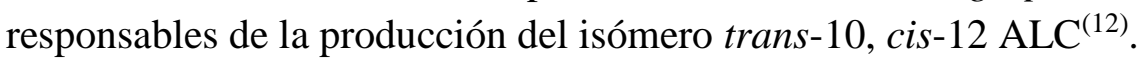

\section{- Isómero trans-10, cis-12 ALC en la teoría de biohidrogenación}

Durante el SDGL aumentan los isómeros trans de los AG C18:1 y C18:2 en la leche, entre ellos el isómero trans-10, cis-12 ALC. Esta observación permitió obtener los primeros indicios del mecanismo de acción para la presencia del SDGL ${ }^{(7,8,9)}$. Con base en ello, se infundieron duodenalmente (para evitar alteraciones por bacterias ruminales) isómeros puros del AG C18:2 con el objetivo de relacionarlos con la caída de grasa en leche ${ }^{(7)}$. Al respecto, Baumgard et al ${ }^{(32)}$ infundieron los isómeros del ALC trans-10 cis- $^{-}$ 12 y cis-9 trans-11 y observaron que el primero reducía la concentración de grasa en leche, mientras que cis-9, trans-11 ALC no tuvo ningún efecto (Figura 2). Posteriormente, de Veth et $a l^{(37)}$ reportaron que la caída de grasa en leche a causa del isómero trans-10, cis-12 ALC se ajusta a una curva de decaimiento exponencial, con reducción de $50 \%$ de grasa en leche a $7.5 \mathrm{~g} \mathrm{~d}^{-1}$ y un máximo de respuesta medio a 3.5 $\mathrm{g} \mathrm{d}^{-1}$ (Figura 3), resultados similares fueron reportados por Shingfield y Griinari ${ }^{(38)}$.

Figura 2: Concentración de grasa en leche durante la infusión abomasal de isómeros del ácido linoleico conjugado (ALC)

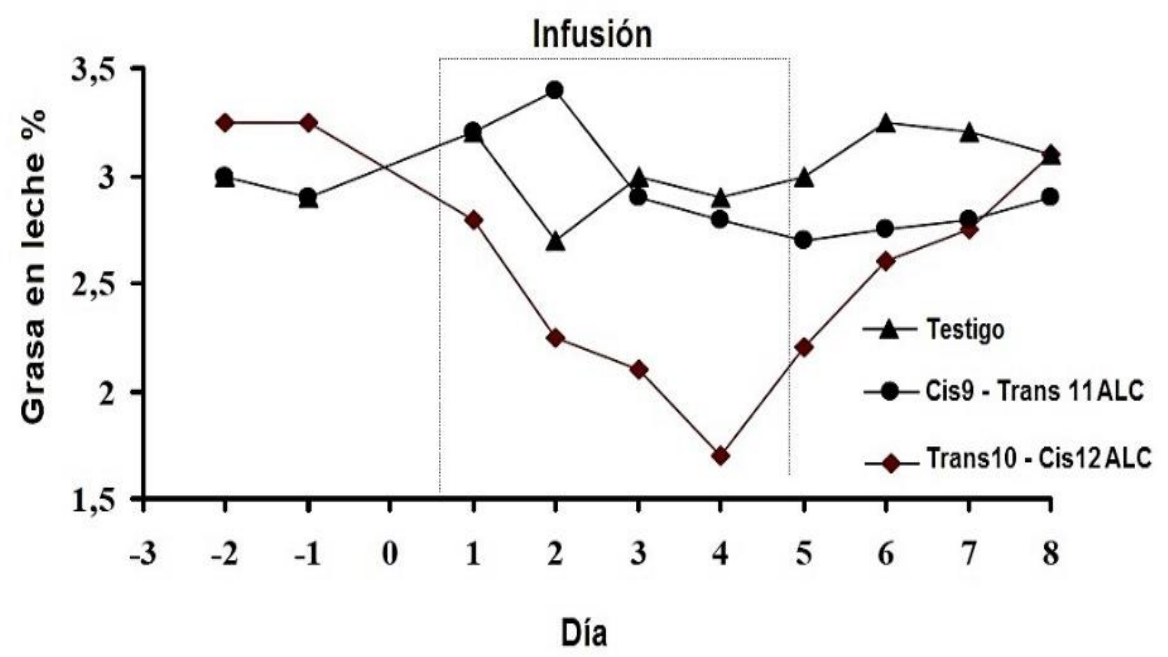

La infusión duró cuatro días y los tratamientos fueron: testigo, cis-9, trans-11 ALC $\left(10 \mathrm{~g} \mathrm{~d}^{-1}\right)$ y trans-10, cis-12 ALC $\left(10 \mathrm{~g} \mathrm{~d}^{-1}\right)$. Fuente: Baumgard et al ${ }^{(32)}$. 
Figura 3: Modelo de decaimiento exponencial que establece la relación entre el cambio en rendimiento de grasa en leche de vaca y la dosis del isómero trans-10, cis-12 ALC

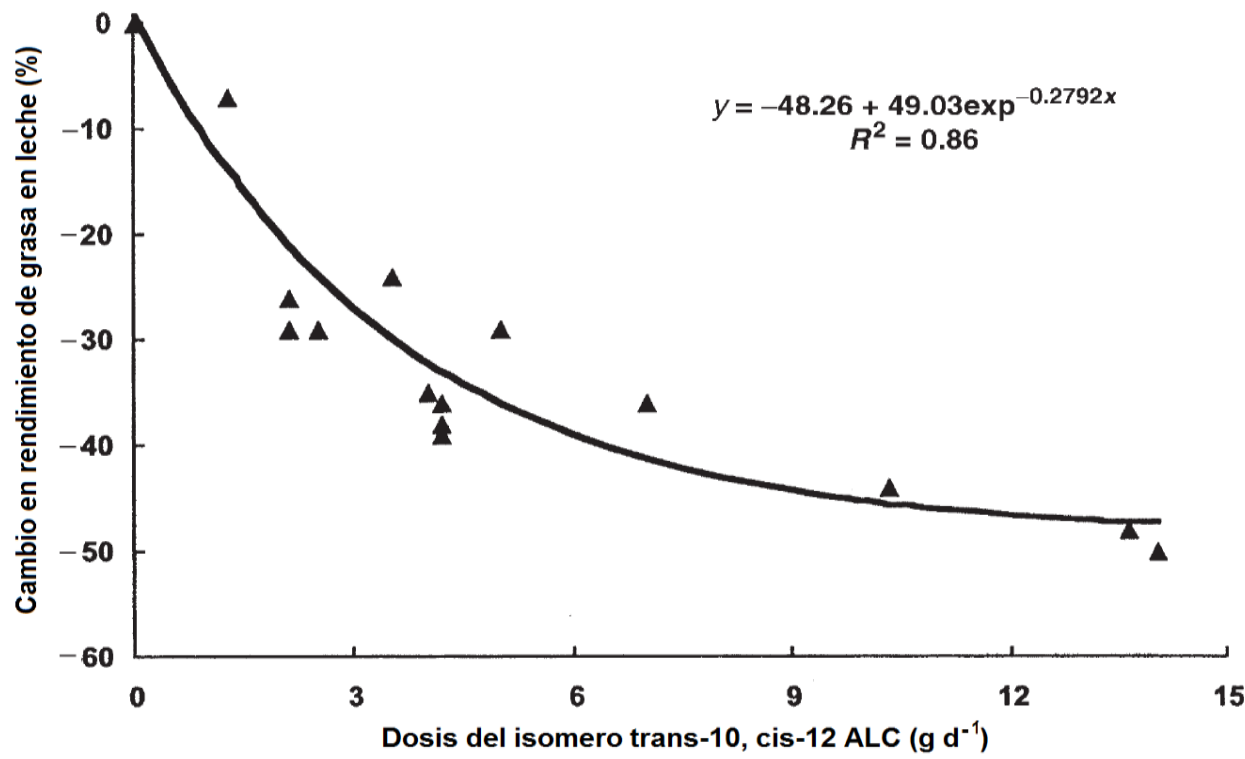

Los valores del modelo para $\mathrm{y}=$ tasa de rendimiento de grasa en leche; para $\mathrm{x}=$ dosis del isómero isómero trans-10, cis-12 ALC; $P<0.001$. Fuente Veth et al $l^{(37)}$.

Si bien, los estudios donde se infundió duodenalmente a vacas lactantes el isómero trans-10, cis-12 ALC han sido de corta duración (<7 días) ${ }^{(37)}$, los resultados son similares a los obtenidos con dietas que inducen SDGL (bajas en FDN o enriquecidas con ácido linoleico y $\alpha$-linolénico), donde la concentración de grasa en leche ha disminuido hasta $50 \%$, y se observaron aumentos del isómero trans-10, cis-12 ALC en leche ${ }^{(8)}$. Existen suplementos alimenticios que contienen el isómero trans-10 cis-12 ruminal protegido, y han sido usados para estudiar su efecto en vacas lactantes en periodos prolongados, desde 6 a 20 semanas $^{(7)}$. En dichos estudios se ha encontrado que la reducción de grasa en leche persiste durante todo el período experimental ${ }^{(39,40)}$ y la concentración de grasa en leche vuelve a la normalidad cuando cesa el suministro del tal isómero ${ }^{(41)}$. No obstante, las dietas de vacas lactantes donde se han incluido aceites de pescado o en general aceites de origen marino, los cuales son ricos en AG insaturados, causan en la grasa láctea de las vacas poco o ningún aumento del isómero trans-10, cis-12 $\mathrm{ALC}^{(8)}$, aunque se observa reducción de la concentración de grasa en leche ${ }^{(42)}$; lo cual sugiere que otros isómeros producidos por biohidrogenación ruminal intervienen en la inhibición de la síntesis de grasa en leche ${ }^{(30)}$. Por ejemplo, incluir los

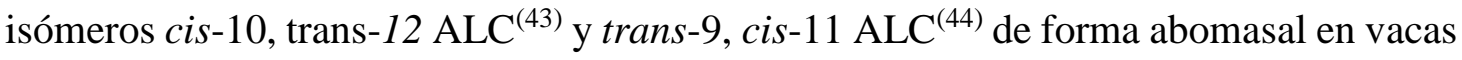
lactantes, reducen la concentración de grasa en leche. Es importante mencionar que en estos estudios solamente se consideró un solo nivel de tales isómeros, por lo que habrá que tener mucha precaución al extrapolar los resultados. Además, la caída de grasa en leche provocada por dichos isómeros no fue tan pronunciada respecto a la provocada 


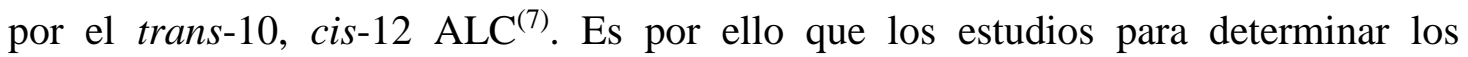
mecanismos de acción de los isómeros que llevan a la presencia del SDGL se han enfocado en el isómero trans-10, cis-12 ALC.

\section{- Mecanismos de acción del trans-10, cis-12 ALC en el SDGL •}

Las dos fuentes de AG en la síntesis de grasa en leche (síntesis de novo y absorción y transferencia de AG preformados) requieren la labor coordinada de un complejo enzimático implicado en el transporte de precursores de AG a la glándula mamaria, la síntesis de novo, la desaturación, esterificación y formación de triglicéridos, $\mathrm{y}$ finalmente la deposición de $\mathrm{AG}$ en leche ${ }^{(16)}$, y es precisamente a través de la inhibición de este complejo enzimático que el isómero trans-10, cis-12 ALC causa la presencia de

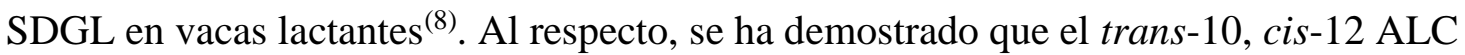
reduce la expresión génica (mRNA) de enzimas lipogénicas, y de factores lipogénicos ${ }^{(44)}$.

A pesar de que los mecanismos de acción del isómero trans-10, cis-12 ALC que reducen la grasa en leche no están claros aun ${ }^{(17)}$, la evidencia científica apunta a que este proceso está regulado por supresión de fragmentos nucleares en la proteína 1 unida al elemento de respuesta de los esteroles (FREP1) ${ }^{(8)}$. El FREP1 es un regulador global de la síntesis de grasa en leche ${ }^{(17)}$, implicado en la regulación de genes lipogénicos en el tejido epitelial mamario ${ }^{(8)}$, en particular a los asociados con la síntesis de novo ${ }^{(45)}$. Al respecto, el grado de supresión de FREP1 es directamente proporcional a la magnitud de la caída en grasa láctea provocada por el isómero trans-10, cis-12 $\mathrm{ALC}^{(8)}$. Sin embargo, los cambios en la expresión del FREP1 no han podido explicar totalmente el mecanismo de acción para la presencia del síndrome de depresión de grasa láctea ${ }^{(17,32)}$, sugiriendo que el isómero trans-10, cis-12 ALC afecta otros factores de transcripción que regulan la síntesis de grasa en leche ${ }^{(44)}$. Al respecto, dietas que provocan SDGL e infusiones abomasales con trans-10, cis-12 ALC modifican la expresión de la hormona tiroidea conocido como $\mathrm{S} 14^{(45)}$, así como los receptores activados por proliferadores de

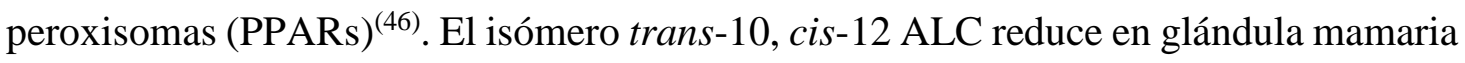
la expresión del PPARs, evidenciando el papel central de este factor de transcripción en la regulación de la síntesis de grasa de la leche de vaca ${ }^{(45)}$. Sin embargo, la función de los PPARs durante el SDGL es debatible ${ }^{(47,48)}$, debido a que el isómero trans-10, cis-12 $^{2}$ ALC redujo la grasa corporal en ratones sin actividad del PPARs ${ }^{(49)}$. No obstante, los adipocitos responden de manera diferencial a las señales moleculares dependiendo del tejido donde se encuentren ${ }^{(50)}$, situación que explicaría la variación en la respuesta del PPARs durante el SDGL ${ }^{(51)}$. Hasta el momento la evidencia científica indica que los 
factores de transcripción afectados por el isómero trans-10, cis-12 ALC, y que explican la reducción de la síntesis de grasa en leche son FREP1, S14 y PPARs. No obstante, es posible existan otras rutas no identificadas ${ }^{(52)}$, y gran parte de la investigación respecto al estudio del SDGL está orientada hacia la identificación de dichas rutas ${ }^{(53)}$, por lo que sería interesante explorarlas, para un mayor entendimiento de la ocurrencia de dicho síndrome.

\section{Efecto del SDGL en la industria lechera}

La industria lechera se ha visto afectada por el efecto que causa el síndrome de grasa láctea, como consecuencia de la implementación de un sistema de fijación de precios a productos lácteos por el departamento de agricultura de Estados Unidos en $2000^{(54)}$. Este acontecimiento desencadenó el pago a productores no solo por concepto de volumen de producción, pero por aquella leche con mayor concentración de grasa y proteína. En consecuencia, los productores del sistema lechero estadunidense han encaminado su producción usando estrategias nutricionales para lograr tal objetivo ${ }^{(55)}$. En el caso de México, no existe regulación por parte del gobierno en los precios de los productos lácteos $^{(56)}$. Sin embargo, algunas empresas lecheras del país pagan incentivos económicos a productores por mayor concentración de grasa y proteína en leche, incrementando de 3 a $8 \%$ el pago por la leche ${ }^{(57)}$. La importancia de ofrecer altas concentraciones de grasa y proteína en leche radica en la relación positiva de dichos componentes y el rendimiento de subproductos como el queso ${ }^{(58)}$. Al respecto, los factores más importantes que afectan el rendimiento en queso son la concentración de grasa y caseína en leche, que en conjunto representan alrededor del $94 \%$ de la materia seca del queso ${ }^{(59)}$, cuyo rendimiento aumenta linealmente con las concentraciones de grasa y caseína en leche. En particular, la concentración de grasa láctea se correlaciona positivamente $(r=0.79)$ con el rendimiento en queso ${ }^{(59)}$. Este comportamiento sugiere, por tanto, que la reducción de la grasa láctea causada por el isómero trans-10, cis-12 ALC, reduce de manera significativa el rendimiento en queso. Al respecto, Schiavon et $a l^{(60)}$ complementaron la dieta de vacas con $5.5 \mathrm{~g} \mathrm{~d}^{-1}$ de trans-10, cis-12, reduciendo $13 \%$ la concentración de grasa en leche, y en consecuencia observaron reducción de $11 \%$ del rendimiento en queso. Por su parte, Chen et al ${ }^{(61)}$, al complementar la dieta de cabras con $6 \mathrm{~g} \mathrm{~d}^{-1}$ de trans-10, cis-12, observaron reducción de $23.2 \%$ en la concentración de grasa en leche, y reducción de $10.2 \%$ en rendimiento en queso. Además, la reducción de grasa en leche de vacas por el isómero trans-10, cis-12 aumenta el tiempo de coagulación de la leche, lo cual reduce la firmeza del queso ${ }^{(60)}$, aspecto que desfavorece la aceptabilidad del queso por los consumidores ${ }^{(59)}$. Con base en estos antecedentes, se asume que el síndrome de depresión de grasa láctea afecta la industria 
lechera al reducir el rendimiento en queso, por lo que el productor al ofertar leche con bajo contenido de grasa recibe menor pago por la misma. Ante esto, es necesario generar estrategias de alimentación que mitiguen la caída de grasa en leche a causa del SDGL.

\section{| Estrategias nutricionales en la mitigación del SDGL \|}

En dietas para vacas lactantes con contenido alto de aceites poliinsaturados (> $5 \%)$, la vitamina $\mathrm{E}$ a dosis mayores de 9,000 $\mathrm{UI} \mathrm{d}^{-1}$ incrementa la concentración de grasa en leche $^{(62)}$ a consecuencia de una mejora en la digestión de la fibra en el rumen ${ }^{(62)}$. Además, estabiliza el pH ruminal ${ }^{(62)}$, lo cual pudiera ayudar a regular el crecimiento de la población de bacterias Megasphaera elsdenii, responsables de la síntesis del isómero

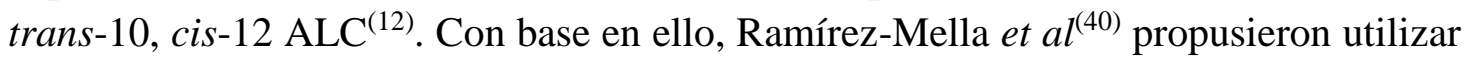
vitamina E para incrementar la concentración de grasa en leche disminuida a consecuencia del isómero trans-10, cis-12 ALC. Sin embargo, no lograron recuperar la concentración de grasa en leche al incluir vitamina E; aunque, observaron un pequeño incremento del isómero cis-9, trans-11 ALC, aspecto que es interesante seguir estudiando para determinar el papel que juega la vitamina E en la síntesis de este isómero del ALC.

Por otro lado, durante el SDGL se reduce la síntesis de todos los AG en la leche de vaca, aunque esta disminución es mayor en la síntesis de AG de cadena corta y cadena media $^{(7,9)}$, lo cual implica que la síntesis de novo es mayormente afectada respecto a la absorción y transferencia de AG preformados ${ }^{(7,8,9)}$. Apoyados con este antecedente, Kadegowda et $a l^{(63)}$ y Vyas et $a l^{(64)}$ formularon la hipótesis que en vacas lactantes se podría recuperar la concentración de grasa disminuida durante el SDGL a consecuencia del isómero trans-10, cis-12 ALC, al suministrarles en la dieta una mezcla de AG de cadena corta y cadena media, bajo el supuesto que el SDGL es producto de una reducción drástica de la síntesis de AG de novo. Sin embargo, en ambos estudios no se logró la recuperación de la grasa en leche, concluyendo que la dosis usada de la mezcla de AG fue insuficiente. En los citados estudios, la recuperación de la grasa en leche no se logró debido a que la mayoría de los AG suplementados no se transfirió a la leche, excepto el ácido palmítico (C16:0), y en promedio su eficiencia de transferencia a la leche fue de $50 \%{ }^{(63,64)}$. Esto implica que inclusiones mayores del C16:0 a vacas lactantes en el SDGL, podrían ayudar a recuperar la concentración de grasa en leche. El C16:0, es un AG importante en la síntesis de triglicéridos en la glándula mamaria, con mayor potencial para incrementar la biosíntesis de lípidos en glándula mamaria ${ }^{(65)}$. Al respecto, la síntesis de triglicéridos consiste en la acilación sucesiva del esqueleto de glicerol-3-fosfato en sus tres átomos de carbono (sn 1, sn 2, sn 3), donde en la primera 
acilación en el sn 1, el sustrato principal de la enzima glicerol-fosfato-acil-transferasa es el C16:0; esta acilación resulta en la formación de ácido lisofosfatídico, el cual es el punto de partida de la síntesis de triglicéridos ${ }^{(66)}$. Por lo tanto, el aumento en la disponibilidad de C16:0 en la glándula mamaria, estimula la síntesis de triglicéridos en leche, lo que en consecuencia incrementa la concentración de grasa en leche ${ }^{(66)}$. Dada la importancia del C16:0 en la síntesis de triglicéridos en glándula mamaria, se han desarrollado complementos con más del $85.0 \%$ de C16:0, los cuales suministrados a vacas lactantes han incrementado la concentración de grasa en leche ${ }^{(65)}$. Por tanto, el C16:0 pudiera ser una opción viable para recuperar la concentración de grasa en leche disminuida por efecto del isómero trans-10, cis-12 ALC.

\section{| Conclusiones}

El síndrome de depresión de grasa láctea se produce por cambios en la biohidrogenación ruminal, que favorece mayor producción de metabolitos que inhiben enzimas involucradas en la síntesis de ácidos grasos. Uno de estos metabolitos es el isómero trans-10, cis-12 ALC, el cual ha tenido atención mayor, y a partir de su estudio se ha consolidado la teoría de biohidrogenación, teoría que explica con mayor solidez el SDGL. Este síndrome, es un problema vigente que afecta la industria lechera al reducir los rendimientos de subproductos lácteos, por lo que el productor recibe menor pago por la leche, y es por ello que son necesarios estudios encaminados a develar los mecanismos que lo provocan, para así diseñar estrategias alimenticias que mitiguen sus efectos negativos.

\section{- Literatura citada:}

1. Jensen RG. The composition of bovine milk lipids: January 1995 to December 2000. J Dairy Sci 2002;85:295-350.

2. Moore JH, Christie WW. Lipid metabolism in the mammary gland of ruminant animals. Prog Lipid Res 1979;17:347-395.

3. Bauman DE, Davis CL. Regulation of lipid metabolism. In: Digestion and metabolism in the ruminant. McDonald IW, Warner AIC editors. Armidale, Australia: Univ New Engl Publ; 1975:496-509. 
4. Jenkins TC, McGuire MA. Major advances in nutrition: impact on milk composition. J Dairy Sci 2006;89:1302-1310.

5. Jenkins TC, Klein CM, Mechor GD. Managing milk fat depression: Interactions of ionophores, fat supplements, and other risk factors. Proc 20th Ann Florida Ruminant Nutr Symp. Gainesville, Florida, 2009.

6. Jenkins TC, Harvatine KJ. Lipids feeding and milk fat depression. Vet Clin Food Anim 2014;623-642.

7. Harvatine KJ, Boisclair YR, Bauman DE. Recent advances in the regulation of milk fat synthesis. Animal 2009;3:40-54.

8. Bauman DE, Harvatine KJ, Lock AL. Nutrigenomics, rumen-derived bioactive fatty acids, and the regulation of milk fat synthesis. Annu Rev Nutr 2011;31:299-319.

9. Bauman DE, Griinari JM. Nutritional regulation of milk fat synthesis. Annu Rev Nutr 2003;23:203-227.

10. Bauman DE, Perfield JWII, Harvatine KJ, Baumgard LH. Regulation of fat synthesis by conjugated linoleic acid: lactation and the ruminant model. J Nutr 2008;138:403-409.

11. Kepler CR, Hirons KP, McNeill JJ, Tove SB. Intermediates and products of the biohydrogenation of linoleic acid by Butyrivibrio fibrisolvens. J Biol Chem 1966;241:1350-1354.

12. Kim YJ, Liu RH, Rychlik JL, Russell JB. The enrichment of a ruminal bacterium (Megasphaera elsdenii YJ-4) that produces the trans-10, cis-12 isomer of conjugated linoleic acid. J Appl Microbiol 2002;92:976-982.

13. Griinari JM, Corl BA, Lacy SH, Chouinard PY, Nurmela KV, Bauman DE. Conjugated linoleic acid is synthesized endogenously in lactating dairy cows by Delta9-desaturase. J Nutr 2000;130:2285-2291.

14. Park Y, Pariza MW. Lipoxygenase inhibitors inhibit heparin-releasable lipoprotein lipase activity in 3T3-L1adipocytes and enhance body fat reduction in mice by conjugated linoleic acid. Biochim Biophys Acta 2001;1534:27-33.

15. Pariza MW. Perspective on the safety and effectiveness of conjugated linoleic acid. Am J Clin Nutr 2004;79:1132S-1136S.

16. Bauman DE, Mather IH, Wall RJ, Lock AL. Major advances associated with the biosynthesis of milk. J Dairy Sci 2006;89:1235-1243.

17. Jenkins TC, Wallace RJ, Moate PJ, Mosley EE. Board-invited review: recent advances in biohydrogenation of unsaturated fatty acids within the rumen microbial ecosystem. J Anim Sci 2008;86:397-412. 
18. Lourenço ME, Ramos-Morales A, Wallace RJ. The role of microbes in rumen lipolysis and biohydrogenation and their manipulation. Animal 2010;4:1008-1023.

19. Palmquist DL, Mattos W. Turnover of lipoproteins and transfer to milk fat of dietary (1-carbon-14) linoleic acid in lactating cows. J Dairy Sci 1978;61:561-565.

20. Bergman EN, Wolff JE. Metabolism of volatile fatty acids by liver and portaldrained viscera in sheep. Am J Physiol 1971;221:586-592.

21. Costa ND, McIntosh GH, Snoswell AM. Production of endogenous acetate by the liver in lactating ewes. Aust J Biol Sci 1976;29:33-42.

22. Annison EF, Linzell JL. The oxidation and utilization of glucose and acetate by the mammary gland of the goat in relation to their over-all metabolism and milk formation. J Physiol 1964;175:372-385.

23. Palmquist DL, Davis CL, Brown RE, Sachan DS. Availability and metabolism of various substrates in ruminants. V. Entry rate into the body and incorporation into milk fat of D(-)ß-hydroxybutyrate. J Dairy Sci 1969;52:633-638.

24. Bauman DE, Davis CL. Biosynthesis of milk fat. In: Lactation: A comprehensive treatise. Larson BL, Smith VR editors. New York: Academic Press; 1974(2):31-75.

25. Ha J, Kim K. Inhibition of fatty acid synthesis by expression of an acetyl-CoA carboxylase-specific ribozyme gene. Proc Natl Acad Sci 1994;91:9951-9955.

26. Knudsen J, Grunnet I. Transacylation as a chain-termination mechanism in fatty acid synthesis by mammalian fatty acid synthetase. Biochem J 1982; 202:139-143.

27. Bauman DE, Brown RE, Davis CL. Pathway of fatty acid synthesis and reducing equivalent generation in mammary gland of rat, sow and cow. Arch Biochem Biophys 1970;140:237.

28. Nafikov RA, Beitz DC. Carbohydrate and lipid metabolism in farm animals. J Nutr 2007;137:702-705.

29. Moore JH, Steele W. Dietary fat and milk fat secretion in cow. Proc Nutr Soc 1968;27:66-70.

30. Bauman DE, Griinari JM. Regulation and nutritional manipulation of milk fat: lowfat milk syndrome. Livest Prod Sci 2001;70:15-29.

31. Collomb M, Schmid A, Sieber R, Wechsler D, Ryhänen EL. Conjugated linoleic acids in milk fat: Variation and physiological effects. Int Dairy J 2006;16:13471361.

32. Baumgard LH, Corl BA, Dwyer DA, Saebo A, Bauman DE. Identification of the conjugated linoleic acid isomer that inhibits milk fat synthesis. Am J Physiol Regul Integr Comp Physiol 2000;278:R179-184. 
33. Shaw JC, Robinson RR, Senger ME. Production of low-fat milk I. Effect of quality and quantity of concentrate on the volatile fatty acids of the rumen and on the composition of the milk. J Nutr 1959;69:244-235.

34. Kim EJ, Huws SA, Lee MRF, Wood JD, Muetzel SM, Wallace RJ, Scollan ND. Fish oil increases the duodenal flow of long chain polyunsaturated fatty acids and trans-11 18:1 and decreases 18:0 in steers via changes in the rumen bacterial community. J Nutr 2008;138:889-896.

35. Bines JA, Hart IC. Metabolic limits to milk production, especially roles of growth hormone and insulin. J Dairy Sci 1982;65:1375-1389.

36. Griinari JM, Dwyer DA, McGuire MA, Bauman DE, Palmquist DL, Nurmela KVV. Trans-octadecenoic acids and milk fat depression in lactating dairy cows. J Dairy Sci 1998;81:1251-1261.

37. de Veth MJ, Griinari JM, Pfeiffer AM, Bauman DE. Effect of CLA on milk fat synthesis in dairy cows: comparison of inhibition by methyl esters and free fatty acids, and relationships among studies. Lipids 2004;39:365-372.

38. Shingfield KJ, Griinari JM. Role of biohydrogenation intermediates in milk fat depression. Eur J Lipid Sci Technol 2007;109:799-816.

39. Glasser F, Ferlay A, Doreau M, Loor JJ. t10, c12-18:2-Induced milk fat depression is less pronounced in cows fed high-concentrate diets. Lipids 2010;45:877-887.

40. Ramírez-Mella M, Hernández-Mendo O, Ramírez-Bribiesca EJ, AméndolaMassiotti RD, Crosby-Galván MM, Burgueño-Ferreira JA. Effect of vitamin E on milk composition of grazing dairy cows supplemented with microencapsulated conjugated linoleic acid. Trop Anim Health Pro 2013;45:1783-1788.

41. Pappritz J, Meyer U, Kramer R, Weber EM, Jahreis G, Rehage J, Flachowsky G, Danicke S. Effects of long-term supplementation of dairy cow diets with rumenprotected conjugated linoleic acids (CLA) on performance, metabolic parameters and fatty acid profile in milk fat. Arch Anim Nutr 2012;65:89-107.

42. Bichi E, Hervás G, Toral PG, Loor JJ, Frutos P. Milk fat depression induced by dietary marine algae in dairy ewes: Persistency of milk fatty acid composition and animal performance responses. J Dairy Sci 2013;96:524-532.

43. Perfield JW, Lock AL, Griinari JM, Saebo A, Delmonte P, Dwyer DA, Bauman DE. Trans-9, cis-11 conjugated linoleic acid reduces milk fat synthesis in lactating dairy cows. J Dairy Sci 2007;90:2211-2218.

44. Baumgard LH, Matitashvili E, Corl B, Dwyer D, Bauman D. Trans-10, cis-12 Conjugated linoleic acid decreases lipogenic rates and expression of genes involved in milk lipid synthesis in dairy cows. J Dairy Sci 2002;85:2155-2163. 
45. Harvatine KJ, Bauman DE. SREBP1 and thyroid hormone responsive spot 14 (S14) are involved in the regulation of bovine mammary lipid synthesis during dietinduced milk fat depression and treatment with CLA. J Nutr 2006;136:2468-2474.

46. Anderson GW, Zhu Q, Metkowski J, Stack MJ, Gopinath S, Mariash CN. The Thrsp null mouse and diet-induced obesity. Mol Cell Endocrinol 2009;302:99-107.

47. Bernard L, Leroux C, Chilliard Y. Expression and nutritional regulation of lipogenic genes in the ruminant lactating mammary gland. Adv Exp Med Biol 2008;606:67-108.

48. Yu Y, Correll PH, Heuvel JP. Conjugated linoleic decreases production of proinflammatory products in macrophages: evidence for a PPAR $\alpha$-dependent mechanism. Biochim Biophys Acta 2002;158:88-99.

49. Peters JM, Park Y, Gonzalez FJ, Pariza MW. Influence of conjugated linoleic acid on body composition and target gene expression in peroxisome proliferatoractivated receptor $\alpha$-null mice. Biochim Biophys Acta 2001;233-242.

50. Gimble JM, Chen C, Pighetti GM, Hitt DC. Adipocyte biology of the bone. In: Ntambi JM, editor. Adipocyte biology and hormone signaling. Washington DC: IOS Press; 2000:231-238.

51. Pariza MW, Park Y, Cook ME. The biologicallyactive isomers of conjugated linoleic acid. Prog Lipid Res 2001;40:283-298.

52. Toral PG, Hervás G, Carreño D, Frutos P. Does supplemental 18:0 alleviate fish oil-induced milk fat depression in dairy ewes? J Dairy Sci 2016;99:1133-1144.

53. Harvatine KJ. Managing milk fat depression. Florida Ruminant Nutr Symp. $27^{\text {th }}$ Ann Meet. Gainesville, Florida; 2016:64-77.

54. Manchester, AC, Blayney DP. Milk pricing in the United States. Agriculture Information Bulletin No. 761, Market and Trade Economics Division, Economic Research Service, U.S.D.A. 2016. http://www.ers.usda.gov/publications/aib761/ aib761fm. Accessed Sep 26, 2016.

55. Erdman RA. Feeding for and the cost of producing milk components: milk fat. Proc 6th Mid-Atlantic Nutr Conf. Timonium MD; 2008:113-121.

56. Secretaría de Economía. "Análisis del sector lácteo en México" 2012. http://www.economia.gob.mx/files/comunidad_negocios/industria_comercio/info rmacionSetorial/analisis_sector_lacteo.pdf. Consultado Oct 17, 2016.

57. CANILEC. El libro blanco de la leche y los productos lácteos. Cámara Nacional de Industriales de la Leche. México: Editorial Litho Offset; 2011. 
58. Fekadu B, Soryal K, Zeng S, VanHekken D, Bah B, Villaquiran M. Changes in goat milk composition during lactation and their effect on yield and quality of hard and semi-hard cheese. Small Ruminant Res 2005;59:55-60.

59. Fox PF, Timothy P, Guinee TP, Cogan M, Paul L, Mcsweeney H. Fundamentals of cheese science. Second ed. USA: Springer New York; 2016.

60. Schiavon S, Cesaro G, Cecchinato A, Cipolat-Gotet C, Tagliapietra F, Bittante G. The influence of dietary nitrogen reduction and conjugated linoleic acid supply to dairy cows on fatty acids in milk and their transfer to ripened cheese. J Dairy Sci 2016;99:1-20.

61. Chen SX, Rovai AL, Lock DE, Bauman TA, Gipson FZ, Zeng SS. Short communication: Effects of milk fat depression induced by a dietary supplement containing trans-10, cis-12 conjugated linoleic acid on properties of semi-hard goat cheese. J Dairy Sci 2009;92:2534-2538.

62. Pottier J, Focant M, Debier C, Buysser De, Goffe G, Mignolet C, Friodmont E, Larondelle Y. Effect of dietary vitamin $\mathrm{E}$ on rumen biohydrogenation pathways and milk fat depression in dairy cows fed high-fat diets. J Dairy Sci 2006;89:685-692.

63. Kadegowda AKG, Piperova LS, Delmonte P, Erdman RA. Abomasal infusion of butterfat increases milk fat in lactating dairy cows. J Dairy Sci 2008;91:2370-2379.

64. Vyas D, Moallem U, Teter BB, Fardin-Kia ARK, Erdman RA. Milk fat responses to butterfat infusion during conjugated linoleic acid-induced milk fat depression in lactating dairy cows. J Dairy Sci 2013;96:2387-2399.

65. Loften RJ, Lin GJ, Drackley KJ, Jenkins CT, Soderholm GC, Kertz FA. Invited review: Palmitic and stearic acid metabolism in lactating dairy cows. J Dairy Sci 2014;97:4661-4674.

66. Hansen HO, Knudsen J. Effect of exogenous long-chain fatty acids on individual fatty acid synthesis by dispersed ruminant mammary gland cells. J Dairy Sci 1987;70:1350-1354. 